\title{
Educational Escape Rooms For Teaching
}

\author{
Rohid Kanakambaran \\ Master of Engineering (Electronics) \\ La Trobe University, Melbourne, Australia \\ rohidtk@gmail.com
}

\begin{abstract}
It's always a challenge for a teacher to get their students to be more engaged or active in the classroom. Engagement happens when students are interested in the subject, have fun, and feel welcome in the classroom. But how do we make students more engaged? To make this happen, Educational escape rooms were introduced into studies. In this paper, we will discuss about the creation and evaluation of educational escape rooms within an engineering learning context. As part of our research project, four educational escape rooms were created for students and surveys were conducted among them to evaluate the success of our project. Our findings indicate that the escape room learning model is well accepted by the students. As a result of the activity, high levels of dedication and enthusiasm are recorded and students shows the eagerness to do more escape room activities.
\end{abstract}

Index Terms - escape rooms, education, student engagement, game based learning

\section{INTRODUCTION}

As a student, it's always difficult to be more attentive in the classroom. Some studies claim that, an average student can be attentive in the classroom for about 10 to 15 minutes, yet most of the classes(university) last 45 to 90 minutes [1]. In order to have a positive impact on students learning experiences, there is an appropriate need for educational technologies and concepts [2].

Thus, traditional education is opening the door to new concepts, such as the inclusion of educational material into a game-based framework. Studies in secondary and higher education mediums have shown that students who have been subject to learning with video games have shown greater comprehension, constancy and encouragement [3]. Another study also shows that students engaged in gamified learning content have increased engagement rates, found learning more interesting and reported higher levels of satisfaction [4].

But how can we add an educational content into a game based network? How will we make it interesting? Educational Escape Rooms are the key to all this queries. An Escape room is a fun and innovative team-based game format in which a team of players work together to find clues, solve puzzles and execute tasks in one or more rooms in order to achieve a specific objective within a limited time period [5].

Escape rooms, in addition to being a popular form of entertainment, have drawn educators interest because of their ability to foster valuable skills such as communication, teamwork, leadership and innovative thinking. Although escape rooms may be expected to be best suited to the early phases of education, this form of gamified experience is treated as an attraction, especially for adults, making it a great fit for students of higher education [5].

Escape Rooms are a team-based activity, and in a team there will usually be between two and ten players. Teamwork is an important factor in this escape game, as there will be puzzles to solve involving more than one player, and everyone will use the skill of each other to get out faster than themselves. Typically, the game starts with a brief reference to the game's rules and how to proceed. The rules of the game and all other things can be explained through an audio, video or via a gamemaster. The timer begins after that and a team gets up to an hour to solve the puzzles and escape the locked room.

Due to the current pandemic (COVID-19), face to face approach of conducting educational escape rooms are not possible, so that an online delivery model of approach is adopted here. For that a JavaScript Web Interface is developed.

This paper is organized into six sections. In Section II, background and survey of educational escape rooms are discussed. Section III deals with the design of 4 educational escape rooms that we have created. Online survey conducted is highlighted in section IV. In Section V, survey results are discussed. The conclusion and future work are eventually discussed in Section VI.

\section{BACKGROUND/SURVEY}

\section{A. Background}

An escape room, also known as an escape game, is a squad based game in which a team of players work together to solve some puzzles and tasks to achieve a specific goal within a limited amount of time [5]. Despite being a relatively new idea, Escape rooms have become extremely popular over the last few years. The first real life escape game originated in Japan around 2007. Currently, Takao Kato of Kyoto publishing company is credited with the world's first real life escape room. After that, escape rooms began to expand and became common in regions such as Asia, North America and Europe. As of November 2019, more than 50,000 escape rooms were estimated worldwide, which shows it's reach around the world [6].

Educational escape rooms are often conducted in a classroom where participants gather in a table-top format and solve puzzles. It is not practical or appropriate to lock a classroom subset in a room and wait for participants to find their way out. So, instead of locking the classroom, a set of locked boxes are used in modern escape rooms. While this form of operation lacks the full immersion of a traditional escape room, it 
can still provide students with inspirational and educational experience when properly designed.

As they promote team building and bonding, escape rooms are now becoming more popular with friends, families and colleagues. A study claims that males and females share an equal interest in escape room activities [5]. Escape rooms usually begins with a story line or a game-style theme. The most prominent among them are prison breaks, bomb defusal and horror.

Breakout EDU, an interactive learning game platform developed in 2015, has popularized academic-focused escape style scenarios [7]. These Breakout EDU games consist of a mixture of physical and digital puzzle elements that need to be completed over a given period of time. The Breakout EDU provides instructors with escape room kits as well. Hundreds of games can be played using each kit.

\section{B. Survey}

This section discusses in detail about how educational escape rooms are created, validation techniques used and also about the advantages and challenges of educational escape rooms.

1) BASIC STRUCTURE FOR CREATING EDUCATIONAL ESCAPE ROOMS: When creating educational escape rooms, there are mainly six areas to consider [8]. They are:

i) Participants ii) Objectives iii) Theme iv) Puzzles

v) Equipment vi) Evaluation

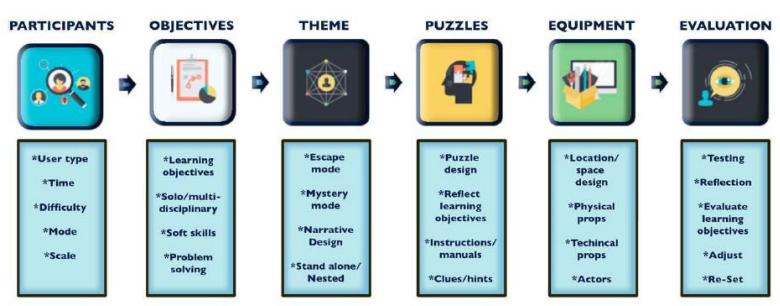

Fig. 1. BASIC STRUCTURE

i) Participants: The first phase in the design of the escape room involves developers knowing their participants and in turn, performing a mini-needs study to target the game interface [8]. At the initial design stage of the escape rooms, this stage of the Participants is divided into five sections.

a) User Type: User needs evaluations are conducted to assess the socioeconomic and educational needs of players.

b) Time: This determines the length of experience.

c) Difficulty: The complexity of puzzles was determined by the level of participants, such as students of high school, undergraduates, postgraduates, etc.

d) Mode: The mode can be split into two, such as Cooperation based and Competitive based modes. In Cooperation mode, all players will work together to solve the puzzles. Whereas, players compete with each other in competitive mode to be the first to work out the results. e) Scale: Choose the number of participants for which the game is planned.

ii) Objectives: Developing the learning objectives is the second step in building an escape room. Developing the goals in the design process for initial game play experience will mean that the experience is purposefully designed and that the concept of the game and puzzles can be developed to reinforce the goals instead of attempting to embed goals in a game that has already been created. This stage of objectives are divided into four segments:

a) Learning Objectives: In order to create a realistic educational game, learning objectives are a must. These objectives can be worked out into the theme, its puzzles and its preferred style to help coordinate the learning plan/results.

b) Solo/Multi-Disciplinary: One discipline or several disciplines described in the experience of the game.

c) Soft Skills: Interactive live action games like escape room games can encourage the growth of soft skills such as teamwork, leadership and communication.

d) Problem solving: Develop opportunities for problemsolving and make the game experience enjoyable for players.

iii) Theme: Developing a strong theme is the third step in creating an escape room. In this step, player motivations, game plot, and content are considered to provide a compelling game play experience to the intended players. Famous themes such as jail breaks, horror, escape the kidnapper, detective mysteries, etc. are used to generate excitement in game play by incorporating objects, scenery, puzzles, music and clues that follow the theme of the room [5]. The theme stage is broken down into four areas:

a) Escape mode: Players need to escape a locked room in a set time

b) Mystery mode: In a set time, solve a mystery.

c) Narrative design: To retain player interest in the game, create a compelling story.

d) Stand-alone/Nested: Assess if the game is a single or part of a larger, nested structure in which several games can be built and played.

iv) Puzzles: The fourth step in developing an escape room is to create puzzles and challenges in which the players will interact throughout the game play experience. Puzzles should be developed in accordance with the steps that have been discussed in the Participants and Objectives phase in particular. This step can be divided into four areas [5]:

a) Puzzle Design: Puzzles are the key content that makes gaming fun and can be configured to meet learning goals.

b) Reflect Learning Objectives: Create puzzles that correspond to the proposed learning objectives and theme.

c) Instructions: A good escape game will have a clear set of instructions and guidelines to help direct players.

d) Hints: Basically, escape rooms are difficult to tackle. Make sure that clues are available and that the method of delivering such clues to the players in the game does not disturb the immersion of the player.

v) Equipment: The fifth step in setting up an escape room is to identify any location/equipment that developers are sup- 
posed to use to enhance their game experience. If technology is to serve the nature of the game, this move could be helpful in understanding and planning how players will interact with the technology and what to do if the technology fails [8]. This step can be broken down into four areas:

a) Location Design: To enjoy the escape room games, retain sufficient moving space and make it comfortable to walk around.

b) Physical Props: To build a compelling and workable experience, Physical props such as puzzles and red herrings plus some general environment items are needed.

c) Technical Props: To enhance the escape room experience, Technical props such as VR, AR, Computers, GPS and location-based recognition are all used.

d) Actors: Actors in real life can make the experience of the Escape Room interesting. Actors can be used as timer indicators, and even they can send out hints if they see any players being stuck.

vi) Evaluation: The last step in building an educational escape room is for developers to determine how to test the escape room game experience. Closely related to the second stage's design concerns: Objectives, developers are asked to consider the methods that they can use to assess whether the game has met the anticipated objectives and results. In developing GBL applications, this stage is considered to be the most important component [8]. This assessment phase is broken down into four areas:

a) Testing: Before conducting an escape game with the intended participants, it is important to evaluate the game experience.

b) Reflection: Reflect with the players about their points of view and their engagement with the game.

c) Evaluate Learning Objectives: Build a comprehensive review of the learning objectives that were built for the experience of the escape game. This can be done by the use of individual preferred approaches.

d) Adjust: To make better decisions on how to modify the game experience, use feedback from the participants.

2) VALIDATION TECHNIQUES USED IN ESCAPE ROOMS: It's very important to know whether or not the puzzles we are solving are right. It was traditionally done by a mentor, simply by reviewing the answers in the answer sheet. Everything has changed today and there are faster ways of checking the answer. There are three basic validation techniques accomplished in the educational escape room games within the table-top format:

Physical combination locks [9]

Computer based locks [10]

Electronic decoder box [11], [12]

i) Physical combination locks

It is one of the earliest validation methods used. These locks are attached to the box with the digits where the treasure is hidden and secured. One needs to figure out the number in order to open the box. There are normally 3-5 digits in a standard lock. Although this strategy proves to be a good, there are still some disadvantages:
- Although the code can normally be changed, it is very time consuming to do so. - The regular physical locks can only handle a limited number of digits. - These types of locks will wear out too quickly over time. So in terms of actual escape rooms, it isn't really effective. - Apart from the locking feature, these types of locks will not have any tracking or timing information on the progress of the learner.

ii) Computer based locks

Computer based method is the another validation technique used in escape rooms. With a computer, phone or tablet, you can access it. The biggest advantage of using a computer-based approach is that it shows the exact time taken to solve a puzzle and tracks the learner's progress as well. There are also some disadvantages, besides the advantages:

- Coordinators must have the technological skills to plan, build and maintain software related to computer-based techniques. - Most individuals prefer to play with physical puzzles and hardware models instead of this machine based approach.

- The computer-based approach would have issues such as WiFi cutting, problems with battery drainage, and software problems that could interfere with the function of the escape room.

iii) Electronic decoder box

One of the finest validation methods to date is electronic decoder boxes. These decoder boxes resolve many of the disadvantages of the previous methods (Physical combination locks and Computer based). Decoder boxes have built-in applications for tracking and timing the progress of learners with data analytics. Moreover, this electronic decoder box has several other features and benefits:

- Simple to use and handle

- User friendly interface and setup

- Configurable countdown timer from 1 minute to 99 minutes

- LCD display for displaying clues, timers and messages

- Three numeric configurable codes, each with a possible length of 1-8 digits

- Automated adjustable hint delivery setup

- 20 hours of battery life, with USB charging as well

- Configurable penalties for incorrect guesses

- Decoder box does not need a WiFi connection or any other technology to operate

The main programming tool used to run the decoder box is Arduino nano. The prime reason for this is that it is very easy to change or upgrade any program with Arduino nano, as well as providing a low-cost platform to handle all the required configurations.

To display the count-down timer, the decoder box uses a 2-line LCD screen. The LCD screen also shows the round, answer code, and can even give hints every 5 minutes by unveiling one digit of the final code. Participants can interact with the decoder using numeric keypad numbers $0-9$, and *. To reset the screen, * key is used. The decoder box is operated by a rechargeable battery with a lifespan of approximately $20+$ hours. It also includes a USB charging port. 


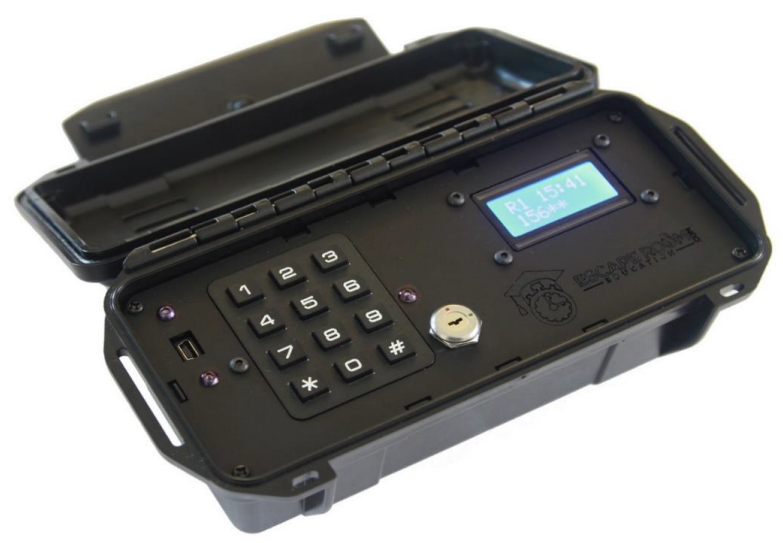

Fig. 2. Third Generation Electronic decoder box

However, the above-mentioned validation strategies are not feasible due to the present circumstances (COVID-19). So, we're using a JavaScript web interface that emulates the features of a physical decoder box.

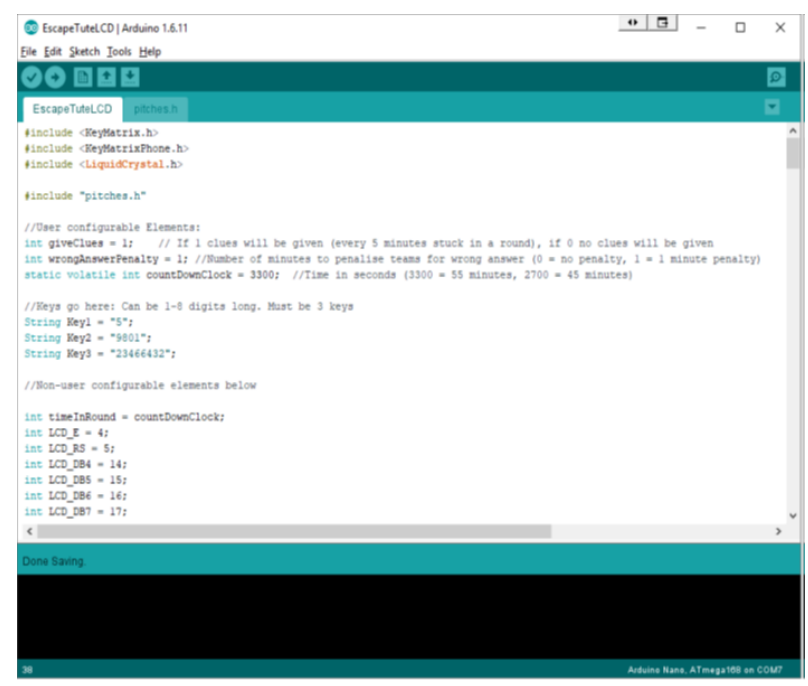

Fig. 3. Decoder program

JavaScript Web Interface

The web interface works exactly the same as the decoder box with additional timer, hint distribution and data analytics features. Instead of the real envelope, as the person completes the puzzle, the next puzzle in the row will automatically appear on the screen with a pop-up window containing the PDF of the puzzle. JavaScript uses the MD5 hash format to store each puzzle's solution. This would deter the participants from attempting to cheat. However, using online tools, MD5 hashes can still be decrypted.

Escape Room participants can interact with each other via an online video conferencing application called Zoom. Using Zoom Breakout rooms, participants can be split into groups of 3-4 individuals. So that the teams can discuss each other and solve the puzzles. In addition to the positive aspects, there are some disadvantages to this online delivery model:

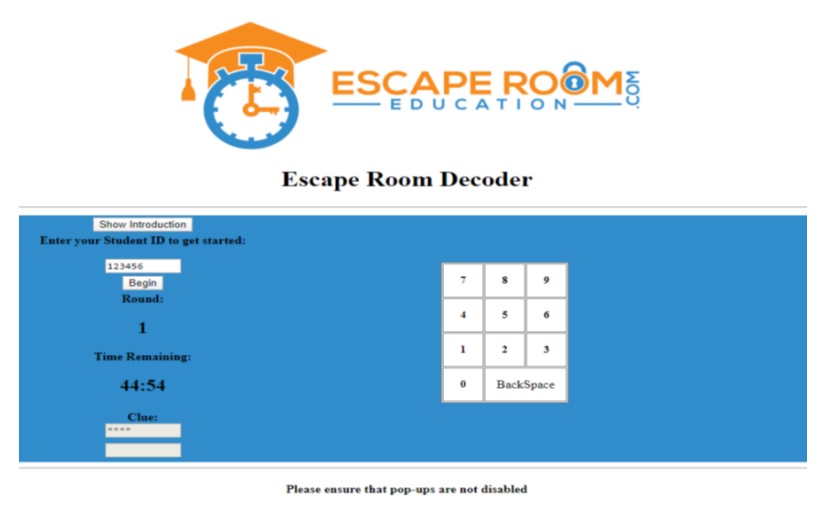

Fig. 4. Escape room web interface

- Bad internet access can disrupt the experience of the escape room.

- Not everybody can adapt to the online model

- Online cheating can be carried out easily

- The number of non-active participants in the online delivery strategy will be higher.

- The other problem is communication barrier

3) ADVANTAGES AND CHALLENGES OF EDUCATIONAL ESCAPE ROOMS: Educational escape rooms have been identified to foster teamwork and cooperation, as well as to produce high levels of enjoyment and engagement [13], [14], [15]. The learning benefits and improved motivations were seen among the students as they find learning more exciting by play [16]. Social contact and communication have also been seen as another common advantage. Creativity, critical thinking and problem solving skills have also been identified as a key advantage, also several studies reported significant increase in leadership skills as well [17], [18]. One of the other benefits is that these escape rooms can be reused with different groups several times [19].

Time commitment is one of the key obstacles in escape rooms, as it is a labor-intensive and resource-intensive operation that does not appeal to many educators because of the analytical and physical work involved in the creation of an escape room. Developing an entertaining story line and designing a series of puzzles that complement it is one of the main challenges for the developers of escape rooms [5]. Another big obstacle for creating an escape room is to change the difficulty level of the puzzles, which is not an easy task for escape game developers. This challenge is much more difficult in academic puzzles, where this adjustment has to be made, taking into account both the difficulty of learning the complexities of the puzzle and the complexity of learning the course materials. Complexity plays a crucial role in the success of the educational escape room game, as relatively simple puzzles can sometimes bore participants, whereas they can contribute to stress or even anxiety if the degree of deficiency is set too high [20]. 


\section{Design/Methodology}

This section discusses in detail about the four different educational escape room games designed as part of our research project. Each escape room consist of three puzzles, which are discussed separately here.

\section{A. Escape Room 1}

Our first escape room was created for EMS5AEE students to teach about cover letters, Hofstede and Safety. Like every educational escape rooms, this one also starts with a story line. For our first escape room activity, a job offer theme has been used. A total of 45 minutes was set aside for this escape room. The puzzles were as follows:

1) Puzzle 1: The first puzzle was about finding errors in the cover letters. A total of 6 mistakes has been given and the participants have to find out at what line the mistakes were and enter the corresponding line number. The solution to the cover letter puzzle is an 8 digit code (13571517). This puzzle was so simple, and it was included in this escape room activity to teach students about the common mistakes they are likely to make when writing a cover letter.

2) Puzzle 2: The second puzzle was about finding different types of safety hazards from the pictures given. A total of 6 hazards has been given and the participants have to find out hazards in each of the given 5 images and enter the code based on the order that appear through various images. A number of research papers were reviewed for this puzzle in order to study various safety risks, such as ride, fall, chemical, ergonomic, trip etc [21], [22].

3) Puzzle 3: The third puzzle was about Hofstede to teach about cultural contexts of various countries. A total of 5 questions has been given and the participants have to find out which country falls in each question and write the number in sequential order for each pair. The solution to the Hofstede puzzle is a 8 digit code (62212526). The 'Hofstede Insights' web page has been used as a basic tool in this puzzle to construct graphs (an example is shown in fig:5) of various countries based on cultural dimensions.

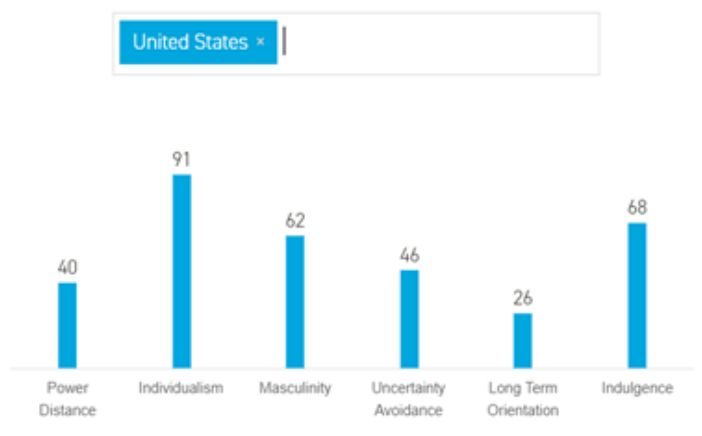

Fig. 5. Example of a graph created from Hofstede insights tool

\section{B. Escape Room 2}

The escape room 2 was designed to teach about Oscilloscopes. Virtual Oscilloscopes (shown in fig: 6) were used as a tool in this escape room to create puzzles (mainly waveforms). For this escape room activity, 'grab a ticket' theme has been used. Like Escape room 1, a total of 45 minutes was given to the participants to solve the puzzles. The puzzles were as follows:

1) Puzzle 1: The first puzzle was to find the frequency of the waveforms given. Four waveforms has been given and the participants have to find the frequency of each waveforms and decode the code. The solution to this puzzle is a 8 digit code (90857035). By solving the first sub-puzzle (shown in fig:7), we will get a two digit code (90). Likewise, by solving the other three sub-puzzles, we will get the remaining 6 digits (857035).

2) Puzzle 2: The second puzzle was to find out the peak to peak voltage of the waveforms given. Like the first puzzle, same pattern has been used in this puzzle as well and the players have to find the peak to peak voltage of each waveforms and decode the code. The solution to this puzzle is a 5 digit code (26106). By solving the first sub-puzzle (shown in fig:8), we will get a two digit code (26). This puzzle was so simple when compared to the puzzle 1 .

3) Puzzle 3: The third puzzle was to find out the duty cycle of waveforms by anaylsing the signals. Three waveforms has been given and the players have to find the duty cycle of each waveforms and decode the code. The solution to this puzzle is a 6 digit code (756530). By solving the first sub-puzzle (shown in fig:9), we will get a two digit code (75).

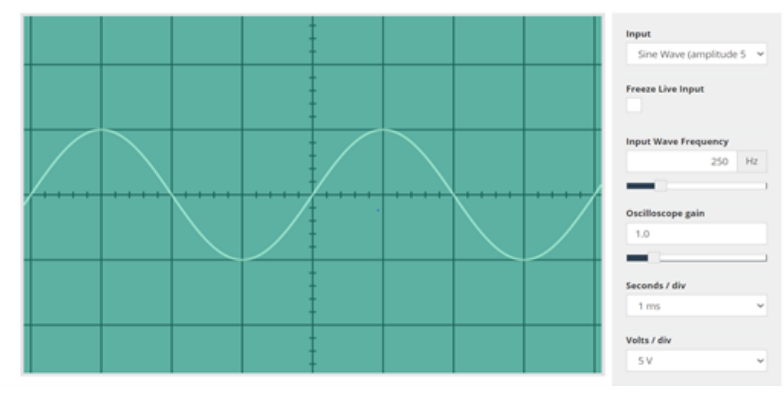

Fig. 6. An interface of virtual oscilloscope

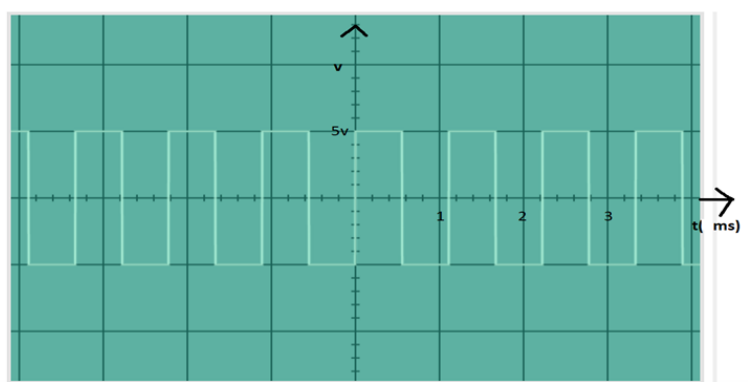

Fig. 7. The puzzle for the first two digits of A

\section{Escape Room 3}

The escape room 3 was designed to teach about the basics of python language. The puzzles were designed to be completed 


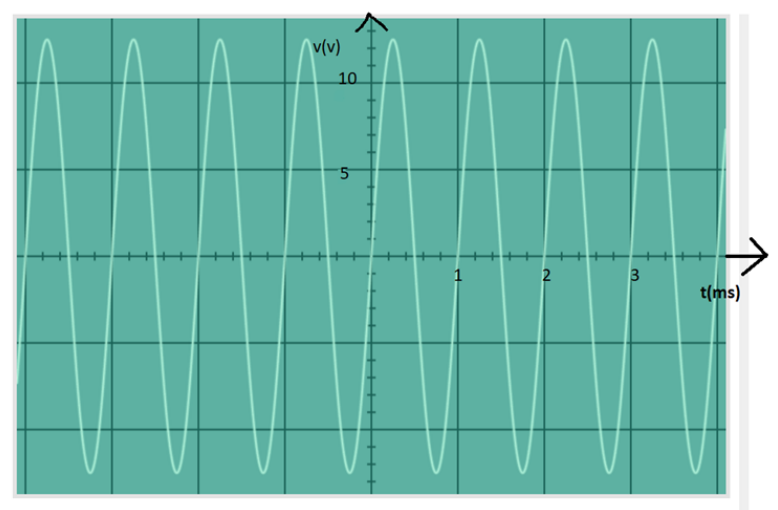

Fig. 8. The puzzle for the first two digits of B

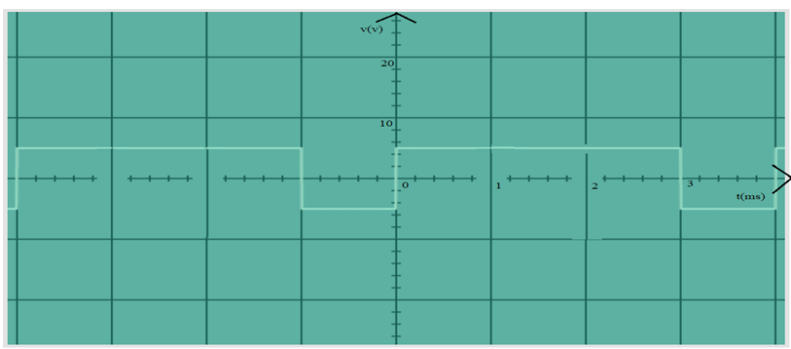

Fig. 9. The puzzle for the first two digits of $\mathrm{C}$

by a short period of time (30 minutes).For the design of this escape room, a lot of information has been gathered from the book: 'Learn Python programming' by Fabrizio Romano . We have used online python compilers (shown in fig:10), to make sure the programs we have created get the right outputs. The puzzles were as follows:

1) Puzzle 1: The first puzzle was about finding errors in the program code. A total of 8 short programs were created for this puzzle. Teams has to find out the errors in the program and use the corresponding line numbers to find the key to escape. The solution to this puzzle is an 8 digit code (42567098). By solving the first sub-puzzle (shown in fig:11), we will get the first digit (4). Likewise, the remaining 7 digits can be solved (2567098).

2) Puzzle 2: The second puzzle was to find the output from the programs given. Four short programs were made for this puzzle. Participants has to find out the output of each program and decode the final code. The solution to this puzzle is a 9 digit code (151153633). By solving the first sub-puzzle (shown in fig:12), we will get the first three digits (151).

3) Puzzle 3: String operations were used in the creation of third puzzle. The pattern is almost similar to that of second puzzle. The players has to find the output of the programs and select it from the options given. The solution to this puzzle is a 6 digit code (412234). By solving the first sub-puzzle (shown in fig:13), we will get the first digit (4). Likewise, the remaining 5 digits can be solved (12234).

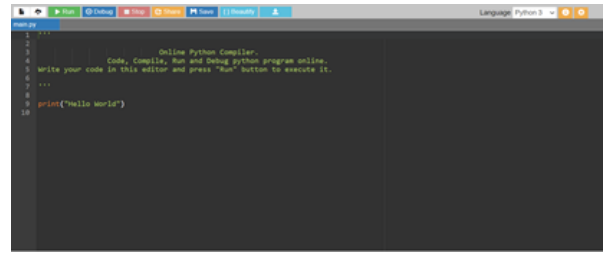

Fig. 10. Interface of an online python compiler

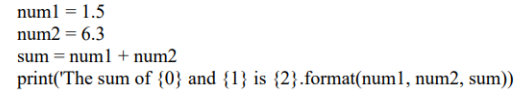

Fig. 11. The puzzle for the first digit of A

\section{Escape Room 4}

The final escape room was designed to teach about the basics of electronics. Unlike the other three escape rooms which has been done with the help of other research member (Harsha Mary Kurian), this one has been done individually. This escape room was little complex when compared to other three escape rooms as it includes some calculations and all. So that a maximum of 60 minutes has been allowed for the participants to solve the puzzles. The puzzles were as follows:

1) Puzzle 1: The first puzzle deals with kirchoff's current and voltage law's. A total of 3 questions has been created and the players have to solve each questions using kirchoff's law and decode the key. The solution to the kirchoff's puzzle is an 8 digit code (29151624). By solving the first sub-puzzle (shown in fig:14), we will get a two digit code (29). Likewise, the remaining 6 digits (151624) can be solved.

2) Puzzle 2: The second puzzle deals with series/parallel RLC circuits. The same pattern of Puzzle 1 has been used and the only difference is with the circuits. The solution to the RLC puzzle is a 6 digit code (212638). By solving the first sub-puzzle (shown in fig:15), we will get a first digit code (2). Likewise, the remaining 5 digits (12638) can be solved.

3) Puzzle 3: The third puzzle was targeted towards teaching about transistor and current limiting resistor. Two questions were created for this puzzle and the pattern used was same as that of other two puzzles. The solution to this puzzle is a 9 digit code (431443300). By solving the first sub-puzzle (shown in fig:16), we will get a first 6 digit code (431443). Remaining 3 digits can be get by solving the current limiting resistor (300).

\section{EVALUATION}

Evaluation is one of the main areas of research that has been conducted to explain the quality of work. It is important to know whether our escape room activities are effective among students in terms of fostering motivation, teamwork, student engagement and awareness. For that purpose, based on our first escape room activity, we have conducted an online survey for students. The kind of survey we carried out was a Likert 


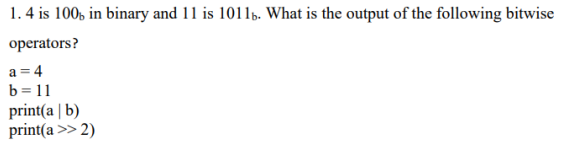

Fig. 12. The puzzle for the first three digits of $B$

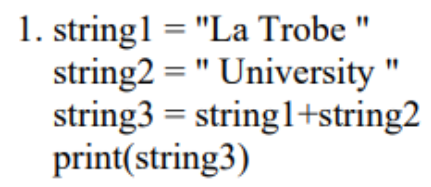
A) La TrobeUniversity
B) LUanTirvoebresity
C) LaTrobeUniversity
D) La Trobe University

Fig. 13. The puzzle for the first digit of $\mathrm{C}$

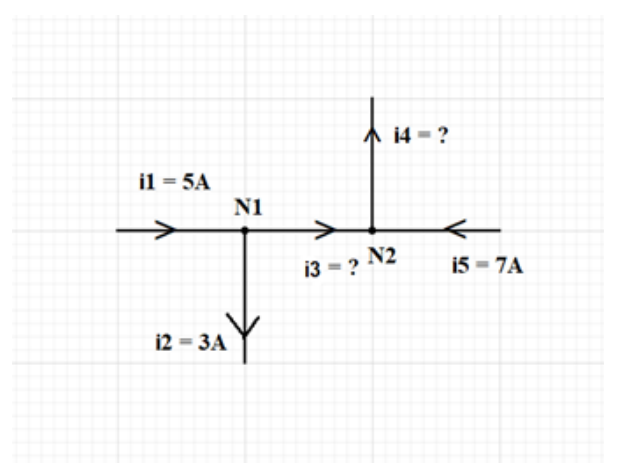

Fig. 14. The puzzle for the first two digits of kirchoff's puzzle

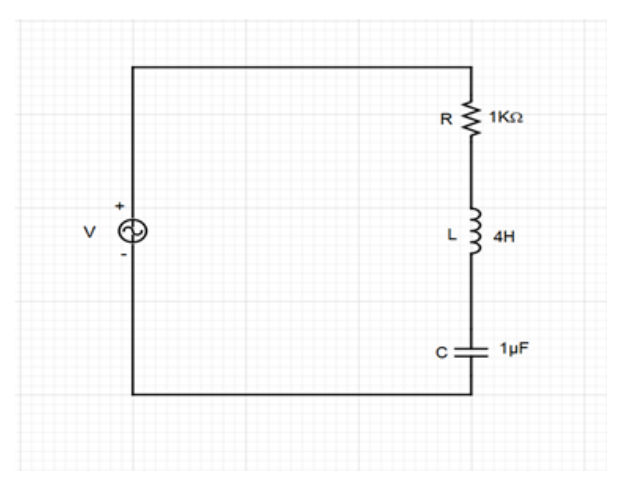

Fig. 15. The puzzle for the first digit of RLC puzzle

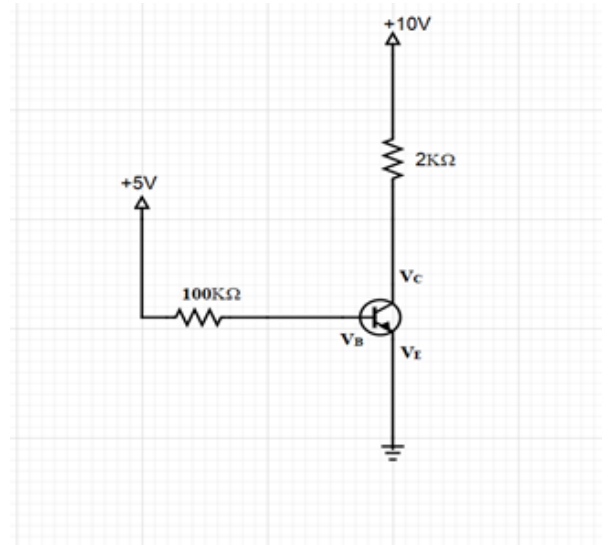

Fig. 16. The puzzle for the first six digits of $\mathrm{C}$

survey (Strongly Disagree to Strongly Agree). Following are the questions that were included for the online survey:

1) How many in-person escape rooms have you done previously?

2) How many educational escape rooms have you done previously?

3) For each puzzle, rank the level of difficulty as you perceived it:

4) For each puzzle, rank how much you enjoyed it:

5) How much do you think you learnt in each of the following three puzzles?

A feedback box was also added at the end of survey section, so that students can post their opinions, ideas, reflections and other comments over there.

\section{RESUlTs/Discussion}

This section discusses about the results of online survey being conducted based on our first escape room activity. A total of 14 students participated in this survey. The majority (75\%) of participants were able to solve the puzzles within the 45 minute time frame.

Based on the survey results, majority of students rated puzzle three (Hofstede) as the most difficult one (shown in Fig.19). When asked about how much they enjoyed on each puzzle, almost $95 \%$ of students ranked that they liked all three puzzles (shown in Fig.20).

Our purpose of conducting an educational escape room activity was for students to learn or benefit something from an activity. For that purpose, we think we have been successful in achieving that as more than $80 \%$ of students rated that they have learnt something from it (shown in Fig.21).

Fig 22 shows the survey results for the most appropriate suited response for the entire activity. In that, 5 out of 14 students rated that they found the activity difficult (although approximately 65\% of participants either 'Disagree' or 'Strongly Disagree' it). Almost 95\% of participants agreed the teamwork aspect of the escape room activity and most students think that the time passed too quickly. Even though some students feel exhausted while doing the escape room 
activity, We are happy to see that almost all students enjoyed and found the escape room activity as satisfying.

We note that of those surveyed, only $75 \%$ of students had done an educational escape room activity before (shown in Fig.18). Only 2 out of 14 had done more than 4 educational escape rooms. However, more than $85 \%$ of participants had done in-person escape rooms previously (shown in Fig.17).

The comments received at the end of the survey were pretty good. Students are asking for more escape room games during workshop sessions as they find it super fun. Overall, the survey results were quite good, which gave us enormous confidence in creating more and more escape rooms.

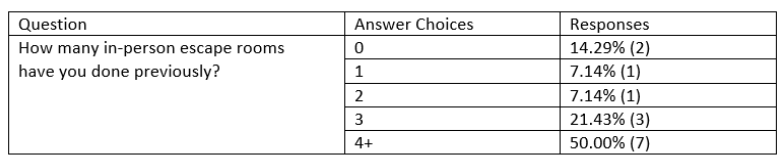

Fig. 17. Survey results 1

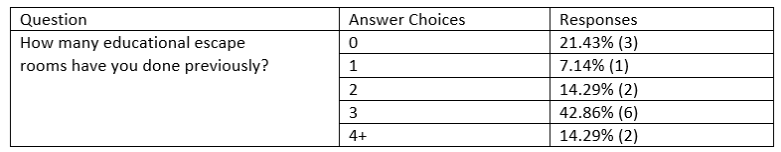

Fig. 18. Survey results 2

\begin{tabular}{|l|c|c|c|c|c|l|l|l|}
\hline Question & & $\begin{array}{l}\text { Very } \\
\text { Easy }\end{array}$ & Easy & Medium & Difficult & $\begin{array}{l}\text { Very } \\
\text { Difficult }\end{array}$ & Total & $\begin{array}{l}\text { Weighted } \\
\text { Average }\end{array}$ \\
\hline $\begin{array}{l}\text { For puzzle } \\
\text { rank the } \\
\text { level of } \\
\text { difficulty } \\
\text { as you } \\
\text { perceived } \\
\text { it: }\end{array}$ & $\begin{array}{c}\text { Puzzle } \\
1\end{array}$ & $\begin{array}{c}7.14 \% \\
1\end{array}$ & $\begin{array}{c}21.43 \% \\
3\end{array}$ & $\begin{array}{c}57.14 \% \\
8\end{array}$ & $\begin{array}{c}14.29 \% \\
2\end{array}$ & $\begin{array}{c}0.00 \% \\
0\end{array}$ & 14 & 2.79 \\
\cline { 2 - 9 } & 2 & $\begin{array}{c}28.57 \% \\
4\end{array}$ & $\begin{array}{c}35.71 \% \\
5\end{array}$ & $\begin{array}{c}21.43 \% \\
3\end{array}$ & $\begin{array}{c}0.00 \% \\
0\end{array}$ & 14 & 2.64 \\
\cline { 2 - 9 } & $\begin{array}{c}7.14 \% \\
3\end{array}$ & $\begin{array}{c}14.29 \% \\
2\end{array}$ & $\begin{array}{c}50.00 \% \\
7\end{array}$ & $\begin{array}{c}14.29 \% \\
2\end{array}$ & $\begin{array}{c}14.29 \% \\
2\end{array}$ & 14 & 3.14 \\
\hline
\end{tabular}

Fig. 19. Survey results 3

\begin{tabular}{|l|l|l|l|l|l|l|l|l|}
\hline Question & & $\begin{array}{l}\text { Strongly } \\
\text { Disliked }\end{array}$ & Disliked & Unsure & Liked & $\begin{array}{l}\text { Strongly } \\
\text { Liked }\end{array}$ & Total & $\begin{array}{l}\text { Weighted } \\
\text { Average }\end{array}$ \\
\hline $\begin{array}{l}\text { For puzzle } \\
\text { rank how } \\
\text { much you } \\
\text { enjoyed } \\
\text { it: }\end{array}$ & $\begin{array}{c}\text { Puzzle } \\
1\end{array}$ & $\begin{array}{c}0.00 \% \\
0\end{array}$ & $\begin{array}{c}0.00 \% \\
0\end{array}$ & $\begin{array}{c}0.00 \% \\
0\end{array}$ & $\begin{array}{c}50.00 \% \\
7\end{array}$ & $\begin{array}{c}50.00 \% \\
7\end{array}$ & 14 & 4.50 \\
\cline { 2 - 9 } & $\begin{array}{c}\text { Puzzle } \\
2\end{array}$ & $\begin{array}{c}0.00 \% \\
0\end{array}$ & $\begin{array}{c}0.00 \% \\
0\end{array}$ & $\begin{array}{c}0.00 \% \\
0\end{array}$ & $\begin{array}{c}42.86 \% \\
6\end{array}$ & $\begin{array}{c}57.14 \% \\
8\end{array}$ & 14 & 4.57 \\
\cline { 2 - 8 } & $\begin{array}{c}\text { Puzzle } \\
3\end{array}$ & $\begin{array}{c}0.00 \% \\
0\end{array}$ & $\begin{array}{c}0.00 \% \\
0\end{array}$ & $\begin{array}{c}0.00 \% \\
0\end{array}$ & $\begin{array}{c}50.00 \% \\
7\end{array}$ & $\begin{array}{c}50.00 \% \\
7\end{array}$ & 14 & 4.50 \\
\hline
\end{tabular}

Fig. 20. Survey results 4

\section{CONCLUSION}

In this paper we discuss about the importance of escape rooms in our educational system. We know that it is difficult for a student to concentrate on a lecture for more than 30 minutes. A study claims that an average student can be

\begin{tabular}{|c|c|c|c|c|c|c|c|c|}
\hline Question & & $\begin{array}{l}\text { Very } \\
\text { Little }\end{array}$ & A Little & Unsure & $\begin{array}{l}\text { Quite a } \\
\text { bit }\end{array}$ & A Lot & Total & $\begin{array}{l}\text { Weighted } \\
\text { Average }\end{array}$ \\
\hline \multirow{3}{*}{$\begin{array}{l}\text { How } \\
\text { much do } \\
\text { you think } \\
\text { you } \\
\text { learn't in } \\
\text { each of } \\
\text { the } \\
\text { following } \\
\text { Puzzles? }\end{array}$} & $\begin{array}{c}\text { Puzzle } \\
1\end{array}$ & $\begin{array}{c}0.00 \% \\
0\end{array}$ & $\begin{array}{c}7.14 \% \\
1\end{array}$ & $\begin{array}{c}0.00 \% \\
0\end{array}$ & $\begin{array}{c}35.71 \% \\
5\end{array}$ & $\begin{array}{c}57.14 \% \\
8\end{array}$ & 14 & 4.43 \\
\hline & $\begin{array}{c}\text { Puzzle } \\
2\end{array}$ & $\begin{array}{c}0.00 \% \\
0\end{array}$ & $\begin{array}{c}7.14 \% \\
1\end{array}$ & $\begin{array}{c}7.14 \% \\
1\end{array}$ & $\begin{array}{c}35.71 \% \\
5\end{array}$ & $\begin{array}{c}50.00 \% \\
7\end{array}$ & 14 & 4.29 \\
\hline & $\begin{array}{c}\text { Puzzle } \\
3\end{array}$ & $\begin{array}{c}0.00 \% \\
0\end{array}$ & $\begin{array}{c}0.00 \% \\
0\end{array}$ & $\begin{array}{c}14.29 \% \\
2\end{array}$ & $\begin{array}{c}21.43 \% \\
3\end{array}$ & $\begin{array}{c}64.29 \% \\
9\end{array}$ & 14 & 4.50 \\
\hline
\end{tabular}

Fig. 21. Survey results 5

\begin{tabular}{|c|c|c|c|c|c|c|c|c|}
\hline Question & & $\begin{array}{l}\text { Strongly } \\
\text { Disagree }\end{array}$ & Disagree & Unsure & Agree & $\begin{array}{l}\text { Strongly } \\
\text { Agree }\end{array}$ & Total & $\begin{array}{l}\text { Weighted } \\
\text { Average }\end{array}$ \\
\hline $\begin{array}{l}\text { Please } \\
\text { Select } \\
\text { the most }\end{array}$ & $\begin{array}{l}\text { I wanted to } \\
\text { complete the } \\
\text { escape } \\
\text { room activity }\end{array}$ & $\begin{array}{c}0.00 \% \\
0\end{array}$ & $\begin{array}{c}0.00 \% \\
0\end{array}$ & $\begin{array}{c}7.14 \% \\
1\end{array}$ & $\begin{array}{c}35.71 \% \\
5\end{array}$ & $\begin{array}{c}57.14 \% \\
8\end{array}$ & 14 & 4.50 \\
\hline \multirow[t]{9}{*}{$\begin{array}{l}\text { suited } \\
\text { response }\end{array}$} & $\begin{array}{l}\text { I found the } \\
\text { activity difficult }\end{array}$ & $\begin{array}{c}21.43 \% \\
3\end{array}$ & $\begin{array}{c}42.86 \% \\
6\end{array}$ & $\begin{array}{c}0.00 \% \\
0\end{array}$ & $\begin{array}{c}28.57 \% \\
4\end{array}$ & $\begin{array}{c}7.14 \% \\
1\end{array}$ & 14 & 2.57 \\
\hline & $\begin{array}{l}\text { I felt that time } \\
\text { passed quickly }\end{array}$ & $\begin{array}{c}0.00 \% \\
0\end{array}$ & $\begin{array}{c}0.00 \% \\
0\end{array}$ & $\begin{array}{c}7.14 \% \\
1\end{array}$ & $\begin{array}{c}35.71 \% \\
5\end{array}$ & $\begin{array}{c}57.14 \% \\
8\end{array}$ & 14 & 4.50 \\
\hline & $\begin{array}{l}\text { I enjoyed the } \\
\text { escape room } \\
\text { activity }\end{array}$ & $\begin{array}{c}0.00 \% \\
0\end{array}$ & $\begin{array}{c}0.00 \% \\
0\end{array}$ & $\begin{array}{c}0.00 \% \\
0\end{array}$ & $\begin{array}{c}21.43 \% \\
3\end{array}$ & $\begin{array}{c}78.57 \% \\
11\end{array}$ & 14 & 4.79 \\
\hline & $\begin{array}{l}\text { I felt l achieved } \\
\text { something in the } \\
\text { escape room } \\
\text { activity }\end{array}$ & $\begin{array}{c}0.00 \% \\
0\end{array}$ & $\begin{array}{c}0.00 \% \\
0\end{array}$ & $\begin{array}{c}7.14 \% \\
1\end{array}$ & $\begin{array}{c}42.86 \% \\
6\end{array}$ & $\begin{array}{c}50.00 \% \\
7\end{array}$ & 14 & 4.43 \\
\hline & $\begin{array}{l}\text { I liked the } \\
\text { teamwork aspect } \\
\text { of the escape } \\
\text { room activity }\end{array}$ & $\begin{array}{c}0.00 \% \\
0\end{array}$ & $\begin{array}{c}0.00 \% \\
0\end{array}$ & $\begin{array}{c}7.14 \% \\
1\end{array}$ & $\begin{array}{c}42.86 \% \\
6\end{array}$ & $\begin{array}{c}50.00 \% \\
7\end{array}$ & 14 & 4.43 \\
\hline & $\begin{array}{l}\text { I became } \\
\text { unaware of my } \\
\text { surroundings } \\
\text { while doing the } \\
\text { escape room } \\
\text { activity }\end{array}$ & $\begin{array}{c}21.43 \% \\
3\end{array}$ & $\begin{array}{c}21.43 \% \\
3\end{array}$ & $\begin{array}{c}14.29 \% \\
2\end{array}$ & $\begin{array}{c}14.29 \% \\
2\end{array}$ & $\begin{array}{c}28.57 \% \\
4\end{array}$ & 14 & 3.07 \\
\hline & $\begin{array}{l}\text { I felt absorbed in } \\
\text { the escape room } \\
\text { activity }\end{array}$ & $\begin{array}{c}7.14 \% \\
1\end{array}$ & $\begin{array}{c}0.00 \% \\
0\end{array}$ & $\begin{array}{c}14.29 \% \\
2\end{array}$ & $\begin{array}{c}50.00 \% \\
7\end{array}$ & $\begin{array}{c}28.57 \% \\
4\end{array}$ & 14 & 3.93 \\
\hline & $\begin{array}{l}\text { I found the } \\
\text { escape room } \\
\text { activity satisfying }\end{array}$ & $\begin{array}{c}0.00 \% \\
0\end{array}$ & $\begin{array}{c}0.00 \% \\
0\end{array}$ & $\begin{array}{c}0.00 \% \\
0\end{array}$ & $\begin{array}{c}57.14 \% \\
8\end{array}$ & $\begin{array}{c}42.86 \% \\
6\end{array}$ & 14 & 4.43 \\
\hline & $\begin{array}{l}\text { I feel exhausted } \\
\text { when } \\
\text { participating in } \\
\text { the escape room } \\
\text { activity }\end{array}$ & $\begin{array}{c}50.00 \% \\
7\end{array}$ & $\begin{array}{c}21.43 \% \\
3\end{array}$ & $\begin{array}{c}0.00 \% \\
0\end{array}$ & $\begin{array}{c}21.43 \% \\
3\end{array}$ & $\begin{array}{c}7.14 \% \\
1\end{array}$ & 14 & 2.14 \\
\hline
\end{tabular}

Fig. 22. Survey results 6

attentive in the classroom for about 10 to 15 minutes, whereas most of the university classes almost last for about 45 to 90 minutes. If the lectures are taught continuously, students will lose interest and they will not be able to concentrate further. So, in order to solve this issue, Escape rooms were introduced into studies to have a positive impact on students learning experiences. As part of our research project, four educational escape rooms were created. For each escape rooms, there were three puzzles. Our first escape room was developed to teach about Cover letters, Safety and Hofstede. Second one was to teach about Oscilloscopes. Third one was about the basics of Python programming and the final escape room was designed to teach about the basics of Electronics.

The first escape room was developed for EMS5AEE students. During their (EMS5AEE students) workshop session, our escape room was used and a survey was conducted at the end of the escape room activity through our Supervisor Dr. Robert Ross. The escape room activity went well and the results of the survey were pretty good as well and got good feedbacks from students too, which gave us immense confidence to do more escape rooms in the future. Due to the COVID-19 outbreak, conventional educational escape rooms 
using electronic decoders are not possible. So that an online delivery model approach is used here.

From our point of view, there is a bright future waiting for the game based learning. As the technology is improving day by day, we can improve the learning experience of students by using VR and AR technologies in our educational escape rooms, which will bring the escape rooms to next level.

\section{REFERENCES}

[1] "The average attention span of student," 2020. [Online]. Available: https://www.opencolleges.edu.au/informed/features/30-tricksfor-capturing-students-attention/: :text=Some psychologists claim the typical,the material and other factors.

[2] P. Serdyukov, "Innovation in education: what works, what doesn't, and what to do about it?" Journal of Research in Innovative Teaching \& Learning, 2017.

[3] P. Fotaris, T. Mastoras, R. Leinfellner, and Y. Rosunally, "Climbing up the leaderboard: An empirical study of applying gamification techniques to a computer programming class." Electronic Journal of e-learning, vol. 14, no. 2, pp. 94-110, 2016.

[4] G. Barata, S. Gama, J. Jorge, and D. Gonçalves, "Engaging engineering students with gamification," in 2013 5th International Conference on Games and Virtual Worlds for Serious Applications (VS-GAMES). IEEE, 2013, pp. 1-8.

[5] S. Nicholson, "Peeking behind the locked door: A survey of escape room facilities," Pozyskano z http://scottnicholson. com/pubs/erfacwhite. pdf, 2015.

[6] "Escape room history and origin," 2020. [Online]. Available: https://en.wikipedia.org/wiki/Escape room

[7] W. Rouse, "Lessons learned while escaping from a zombie: designing a breakout edu game," The History Teacher, vol. 50, no. 4, pp. 553-564, 2017.

[8] S. Arnab and S. Clarke, "Towards a trans-disciplinary methodology for a game-based intervention development process," British journal of educational technology, vol. 48, no. 2, pp. 279-312, 2017.

[9] S. Clarke, D. J. Peel, S. Arnab, L. Morini, H. Keegan, and O. Wood, "escaped: a framework for creating educational escape rooms and interactive games for higher/further education," International Journal of Serious Games, vol. 4, no. 3, pp. 73-86, 2017.

[10] J. Cain, "Exploratory implementation of a blended format escape room in a large enrollment pharmacy management class," Currents in Pharmacy Teaching and Learning, vol. 11, no. 1, pp. 44-50, 2019.

[11] R. Ross, "Design of an open-source decoder for educational escape rooms," IEEE Access, vol. 7, pp. 145 777-145 783, 2019.

[12] R. Ross and S. Bennett, "Increasing engagement with engineering escape rooms," IEEE Transactions on Games, 2020.

[13] A. M. Ho, "Unlocking ideas: Using escape room puzzles in a cryptography classroom," Primus, vol. 28, no. 9, pp. 835-847, 2018.

[14] R. Peleg, M. Yayon, D. Katchevich, M. Moria-Shipony, and R. Blonder, "A lab-based chemical escape room: Educational, mobile, and fun!" Journal of Chemical Education, vol. 96, no. 5, pp. 955-960, 2019.

[15] X. C. Zhang, G. Diemer, H. Lee, R. Jaffe, and D. Papanagnou, "Finding the "qr'to patient safety: applying gamification to incorporate patient safety priorities through a simulated 'escape room'experience," Cureus, vol. 11, no. 2, 2019.

[16] B. Walsh and M. Spence, "Leveraging escape room popularity to provide first-year students with an introduction to engineering information," Proceedings of the Canadian Engineering Education Association (CEEA), 2018.

[17] V. Adams, S. Burger, K. Crawford, and R. Setter, "Can you escape? creating an escape room to facilitate active learning," Journal for Nurses in Professional development, vol. 34, no. 2, pp. E1-E5, 2018.

[18] T. Foster and S. Warwick, "Nostalgia, gamification and staff development-moving staff training away from didactic delivery," Research in Learning Technology, vol. 26, 2018.

[19] A. Kinio, L. Dufresne, T. Brandys, and P. Jetty, "Break out of the classroom: The use of escape rooms as an alternative learning strategy for surgical education," Journal of Vascular Surgery, vol. 66, no. 3, p. e76, 2017.

[20] M. Hermanns, B. Deal, S. Hillhouse, J. B. Opella, C. Faigle, R. H. Campbell IV et al., "Using an" escape room" toolbox approach to enhance pharmacology education," 2017
[21] T. A. Bentley and R. Haslam, "Identification of risk factors and countermeasures for slip, trip and fall accidents during the delivery of mail," Applied ergonomics, vol. 32, no. 2, pp. 127-134, 2001.

[22] S. G. Luxon, Hazards in the chemical laboratory, 1992. 